\title{
Visible Spectrophotometric Method for the Determination of Pharmaceutically Important Aromatic Primary Amines by using P-N, N-Dimethylphenylenediamine and Iodine
}

\author{
M.Srinivasulu ${ }^{1}$, Elisha Divakar .Tella ${ }^{2 *}$ \\ ${ }^{1}$ Research scholar PG department of chemistry, Noble college, Machilipatnam \\ ${ }^{2}$ Reader \& Head, Department of Chemistry, Noble College (Autonomous), Machilipatnam, A.P. \\ India. \\ *divakartella@gmail.com
}

\begin{abstract}
N, N$-dimethylphenylenediamine (DMPD) is oxidized with Iodine into $p$ - $N, N$ - dimehyl benzo qui none monoimine which can form a purple-red charge-transfer complex with aromatic primary amine (APA) at $p H$ 3.0. The absorbance of the $p$ - $N, N$-dimehylbenzoquinonemonoimine - APA charge-transfer complex is mea sured at 520nm. This proposed method is simple, rapid and sensitive with reasonable precision and accuracy. The precision of the method was found by analyzing a set of eight solutions, each containing a final concentration value approximately in the middle of the Beer's law range. The percent relative standard deviation in this method is presented in table-1. The accuracy of the method was determined by taking different known amounts (with in Beer's law limits) of the drug and analyzing them by proposed method. The results are given in table-2. In the determination of APA the excipients usually present in formulations did not interfere.
\end{abstract}

Keywords: Spectrophotometer, APA, DMPD, Iodine, Buffer pH 3.0.

\section{INTRODUCTION}

The wide distribution of amines in nature, their importance in industry as raw materials, intermediates and finished products and their use in the laboratory causes continuous interest in the analytical problems connected with them. These are focused at two levels, functional level (nitrogen atom and its immediate vicinity) and the molecular level (the interactions between the amino group and the rest of the molecule). The primary aromatic amines are compounds having an amino group directly attached to aromatic nucleus. The substituted anilines fall into two main divisions: (A) those in which one or more hydrogen atoms attached to the aromatic nucleus are replaced by substituents (nucleo substituted anilines). (B) Those in which one or both of the hydrogen atoms of the amino group are replaced.

Many drugs such as shown in table 1 contain primary aromatic amino group. Few drugs attain primary aromatic amino group only after performing hydrolysis (e.g. $\mathrm{N}$-acyl derivatives, cyclic compounds) or reduction (e.g. nitro derivatives). Most of the available methods for the assay of drugs (shown in table 1) in bulk samples, dosage forms and biological fluids (where the solutions are first deproteinised with trichloroacetic acid) are based on the characteristic reaction of primary aromatic amino group. Colorimetric methods constitute the main part of the literature on the subject, in books ${ }^{1-5}$ and treatises on general analysis, as well as in original apaers and reviews ${ }^{6,7}$.The author has summarized typical identification and assay procedures in the case of primary aromatic amines so-far reported basing on the colour development. Oxidations of amines usually yield degradation products, some of which provide indirect evidence for the presence of different types of amines ${ }^{4,8,9}$ Korotkova and co-workers presented two methods, which are based on the spectrophotometric determination of the quinine-imine formed from aniline and amidopyrine by their simultaneous oxidation with hexacyanoferrate(III) ${ }^{10}$ or iodine ${ }^{11}$ The condensation of primary amines with carbonylcomponds was first reported by schiff ${ }^{12}$ and the condensation products are often referred to as Schiff bases (azomethines ).The reaction was reviewed ${ }^{12,13}$. 


\section{EXPERIMENTAL}

\subsection{Preparation of Reagents}

DMPD Solution (0.05\%): It was freshly prepared by dissolving $50 \mathrm{mg}$ of the Analytical grade substance in $100 \mathrm{ml}$ of water.

Iodine Solution (0.005M): $25.4 \mathrm{~g}$ of iodine and $40 \mathrm{~g}$ of potassium iodide were dissolved in 1 litre of distilled water and standardized with sodium arsenite solution. The solution was 20 times diluted further to desired concentration in the experimental work.

Buffer solution (pH3.0): It was prepared by mixing $50 \mathrm{ml}$ potassium acid phthalate $(0.2 \mathrm{M})$ and 40.8 $\mathrm{ml}$ of hydrochloric acid $(0.1 \mathrm{M})$ and $109.2 \mathrm{ml}$ of water.

Primary Aromatic Amines: used were commercially available G.R., I.P, or B.P., grade. Their stock solutions were prepared in distilled water, the compounds insoluble in water being dissolved initially in the minimum amount of dilute hydrochloric acid or sodium hydroxide solution if necessary .Working solutions were prepared by appropriate dilution of the stock solutions after the neutralization of the excess acid or alkali. The $\mathrm{pH}$ of the final diluted solution was brought in the range of 3.0-5.0.

All the other chemical reagents were of analytical grade.

\subsection{Instrumentation}

Spectral and absorbance measurements were made on Shimadzu double beam spectrophotometer UV - 140 with $1 \mathrm{~cm}$ quartz cells $\mathrm{pH}$ measurements were carried out using Systronics $\mathrm{pH}$ meter 335.

\subsection{Absorbance curve}

The absorbance curve of APA in the presence of appropriate reagents was scanned on a spectrophotometer in the range 400-700 nm against the reagent blank. However, the maximum characteristic absorption is obtained at $530 \mathrm{~nm}$. The results were graphically represented in Fig-1.

\subsection{Optical Characteristics - Adherence to Beer's law}

In order to know the Beer's law limits of the proposed method, the absorbances of a series of solutions containing varying amounts of APA and specified concentrations of the remaining as given in the procedure in a total volume of $25 \mathrm{ml}$ were measured at $520 \mathrm{~nm}$ against a reagent blank. The linearity of plots between absorbance and the concentration of APA shows that the system obeys Beer's Law (Fig.-2).

The Beer's law limits, regression equation, correlation coefficient, molar absorptivity, sandell's sensitivity,optimum photometric range were calculated and recorded in Table-3.

\subsection{Procedure}

General Procedure Compounds Containing Free Primary Aromatic Amine: To a $25 \mathrm{ml}$ volumetric flask, these solutions were added in the following order : $15 \mathrm{ml}$ of buffer solution (pH $3.0 \pm 0.1$ ), PDA , $\mathrm{NaIO}_{4}$ and primary aromatic amine. The solution was then diluted to the mark. The absorbance was measured at $(530 \mathrm{~nm})$ after maximum colour development against the reagent blank prepared under similar conditions.

The aromatic amines concentration of the sample solution was deduced from the standard calibration curve.

Procedure for Compounds which Yield Primary Aryl Amino Group on Reduction: About $10 \mathrm{mg}$ of sample solution was accurately weighed and treated with $10 \mathrm{ml}$ of $4 \mathrm{~N}$ hydrochloric acid and $0.25 \mathrm{~g}$ of zinc dust was added in positions after standing for $1 \mathrm{hr}$. at room temperature, the solution was filtered through cotton wool, the residue was washed with $\mathbf{3}+\mathbf{5} \mathrm{ml}$ portions of water and excess $\mathrm{HCl}$ present in filtrate was removed under vacuum and the total volume was brought to $100 \mathrm{ml}$ after bringing the $\mathrm{pH}$ between 5.0 and 7.0. The general procedure was then applied.

Procedure for Compounds which Yield Primary Aromatic Amino Group on Hydrolysis: About $25 \mathrm{mg}$ of sample was boiled under reflux with $20 \mathrm{ml}$ of $4 \mathrm{~N}$ hydrochloric acid for $1 \mathrm{hr}$. under reflux, and the excess $\mathrm{HCl}$ was removed under vacuum .The residue was dissolved in $50 \mathrm{ml}$ of water and diluted to $250 \mathrm{ml}$ after keeping the $\mathrm{pH}$ between 5.0 - 7.0 .Then the general procedure was followed. 
Visible Spectrophotometric Method for the Determination of Pharmaceutically Important Aromatic Primary Amines by using P-N, N-Dimethylphenylenediamine and Iodine

\subsection{Procedure for the Determination of Amines in Pharmaceutical Preparations}

for Tablets: 20 tablets were weighed and powered into a fine_granules, The samples of powder equivalent to $100 \mathrm{mg}$ of the primary aromatic amine was transferred to a centrifuge tube and extracted with $20 \mathrm{ml}$ of alcohol. The solution was filtered_and the residue was washed with alcohol . Filtrate and washings were diluted to $100 \mathrm{ml}$ with distilled water.

Accuracy of the method: The accuracy of the method was determined by taking aliquots containing known quantities of each aromatic primary amine and estimated them by proposed method and the results were tabulated in Table-2.

Precision of the method: The precision of the method was found by analyzing set of eight solutions, each containing a final concentration value approximately in the middle of the Beer's law range. The $\%$ RSD and percent range of errors (for confidence limits $\mathrm{p}=005$ and 0.01 levels) in method are presented in table -3

I) Recovery Experiments: To study the recovery and accuracy of the proposed method, statistical study was done. A fixed, amount of sample was accurately weighed in a series of $25 \mathrm{ml}$ standard flasks and three different level of standard stock solution were added separately. Each level of the added drug was repeated seven times. The total amount drug was then determined by the proposed method. The percent recovery was calculated in the usual way. The results of accuracy testing experiments are presented in Table- 4 .

Of the various reagents studied so far the author felt that DMPD $-I_{2}$ is the best chromogenic reagent in the spectrophotometric determination estimation of sulphacetamide was carried out of primary aromatic amines at $\mathrm{pH} 3.0 \pm 0.1$.

\section{RESUlTS AND DisCUSSION}

The proposed method is simple, rapid and sensitive with reasonable precision and accuracy and it is useful for the determination of some typical and pharmaceutically important aromatic primary amines in bulk sample and pharmaceutical preparations. Though HPLC method is more accurate and rapid, it is expensive.

Comparison of the results incorporated in Tables reveal that the proposed method is rapid, sensitive and simple with reasonable precision and accuracy. Sensitivity of the method is better than many of the methods.

\subsection{Chemistry Involved}

Iodine can oxidize DMPD into p-N-N-dimethylbenzoquinonemonoimine. Which can form a purple red p-N-N-dimethylbenzoquinonemonoimine - aromatic primary amines charge-transfer complex with aromatic primary amines at $\mathrm{pH} 3.0$. Which can be measured at $530 \mathrm{~nm}$.

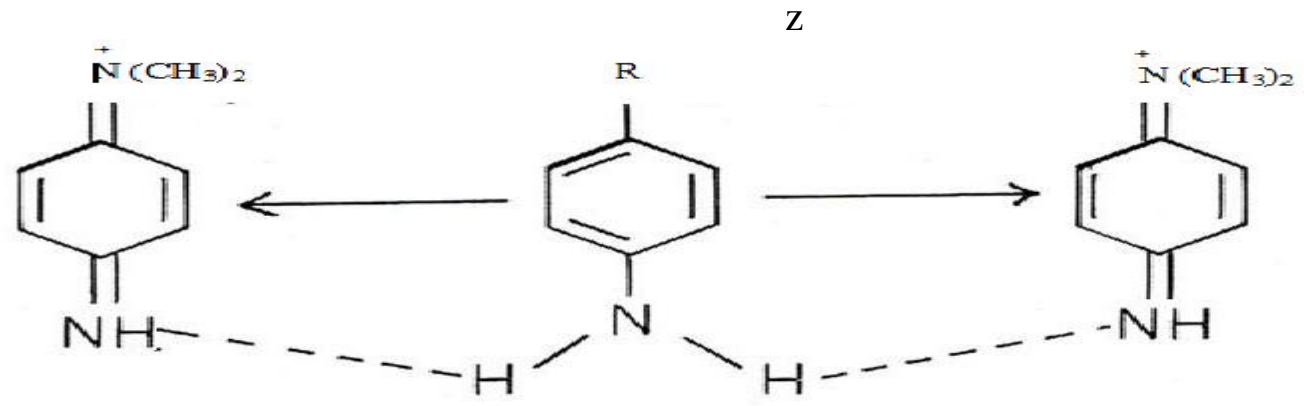

Table1. Optical Characteristics

\begin{tabular}{|c|c|c|c|c|}
\hline Compound & $\begin{array}{l}\text { Beer's law } \\
\text { limits } \\
\mu \mathrm{g} / 25 \mathrm{ml}\end{array}$ & $\begin{array}{l}\text { Molar } \\
\text { absorptivity } \\
\text { 1. } \text { mol }^{-1} \cdot \mathrm{cm}^{-1} \mathrm{X10}^{-3}\end{array}$ & $\begin{array}{l}\text { Optimum } \\
\text { photometric } \\
\text { Range } \mu \mathrm{g} / 25 \mathrm{ml}\end{array}$ & $\begin{array}{c}\text { Sandal's } \\
\text { sensitivity } \\
\mu \mathrm{g} / \mathrm{cm}^{2} / 0.001 \\
\text { absorbance unit }\end{array}$ \\
\hline Procaine & $50-375$ & 6.09 & $100-400$ & 0.038 \\
\hline Dapsone & $25-350$ & 13.54 & $100-300$ & 0.018 \\
\hline Sulphanilamide & $25-400$ & 6.60 & $100-400$ & 0.026 \\
\hline
\end{tabular}


M.Srinivasulu \& Elisha Divakar .Tella

\begin{tabular}{|l|l|l|l|l|}
\hline \hline Sulphacetamide & $50-450$ & 6.40 & $150-400$ & 0.040 \\
\hline Sulphapyridine & $50-400$ & 6.45 & $150-400$ & 0.038 \\
\hline Sulphadiazine & $50-500$ & 7.00 & $150-400$ & 0.042 \\
\hline Sulphamerazine & $50-450$ & 7.04 & $100-350$ & 0.040 \\
\hline Sulphamethopyridiazine & $50-500$ & 7.00 & $150-400$ & 0.040 \\
\hline Sulphadimidine & $50-400$ & 6.95 & $150-400$ & 0.040 \\
\hline Sulphamethizole & $50-300$ & 6.75 & $150-325$ & 0.040 \\
\hline Sulphasomidine & $50-550$ & 5.80 & $175-550$ & 0.040 \\
\hline Sulphamoxole & $50-350$ & 6.67 & $100-350$ & 0.040 \\
\hline Phthalyloulpha-thiazole & $50-400$ & 4.06 & $125-325$ & 0.028 \\
\hline Chloramphenicol & $100-400$ & 4.03 & $200-450$ & 0.080 \\
\hline Folic acid & $100-400$ & 5.88 & $125-400$ & 0.075 \\
\hline
\end{tabular}

Table2. Accuracy of the Method

\begin{tabular}{|l|l|l|l|}
\hline Compound & Amount Taken & (Mg) Found & \% Error \\
\hline Procaine & 375 & 377 & 0.50 \\
\hline Dapsone & 525 & 527 & 0.38 \\
\hline sulphapyridine & 500 & 497 & -0.60 \\
\hline sulphadiazine & 225 & 224 & -0.45 \\
\hline Sulphadimidine & 150 & 149 & -0.66 \\
\hline sulphamethizole & 150 & 151 & 0.66 \\
\hline sulphacetemide & 425 & 427 & 0.49 \\
\hline sulphanilamide & 425 & 421 & 0.98 \\
\hline Phthalyloulpha-hiazole & 150 & 149 & -0.66 \\
\hline Chloramphenicol & 175 & 173 & -1.10 \\
\hline Folic acid & 175 & 176 & 0.58 \\
\hline
\end{tabular}

Table3. Precision of the Method

\begin{tabular}{|l|l|l|l|}
\hline Compound & Standard Deviation & Probability 95\% & Limits 99\% \\
\hline Procaine & 0.014 & 0.5620 .024 & $0.36 \pm 4.0056$ \\
\hline Dapsone & 0.016 & $0.58 \pm 0.018$ & $0.38 \pm 0.029$ \\
\hline sulphapyridine & 0.011 & $0.32 \pm 0.012$ & $0.32 \pm 0.018$ \\
\hline sulphadiazine & 0.007 & $0.37 \pm 0.007$ & $0.37 \pm 0.011$ \\
\hline Sulphadimidine & 0.009 & $0.49 \pm 0.009$ & $0.49 \pm 0.014$ \\
\hline sulphamethizole & 0.015 & $0.46 \pm 0.016$ & $0.46 \pm 0.025$ \\
\hline sulphacetemide & 0.004 & $0.49 \pm 0.004$ & $0.49 \pm 0.006$ \\
\hline sulphanilamide & 0.005 & $0.36 \pm 0.005$ & $0.36 \pm 0.008$ \\
\hline Phthalyloulpha-thiazole & 0.020 & $0.23 \pm 0.021$ & $0.28 \pm 0.02$ \\
\hline Chloramphenicol & 0.020 & $0.30 \pm 0.021$ & $0.30 \pm 0.033$ \\
\hline Folic acid & 0.018 & $0.22 \pm 0.018$ & $0.22 \pm 0.029$ \\
\hline
\end{tabular}

Table4. \% Recovery Data

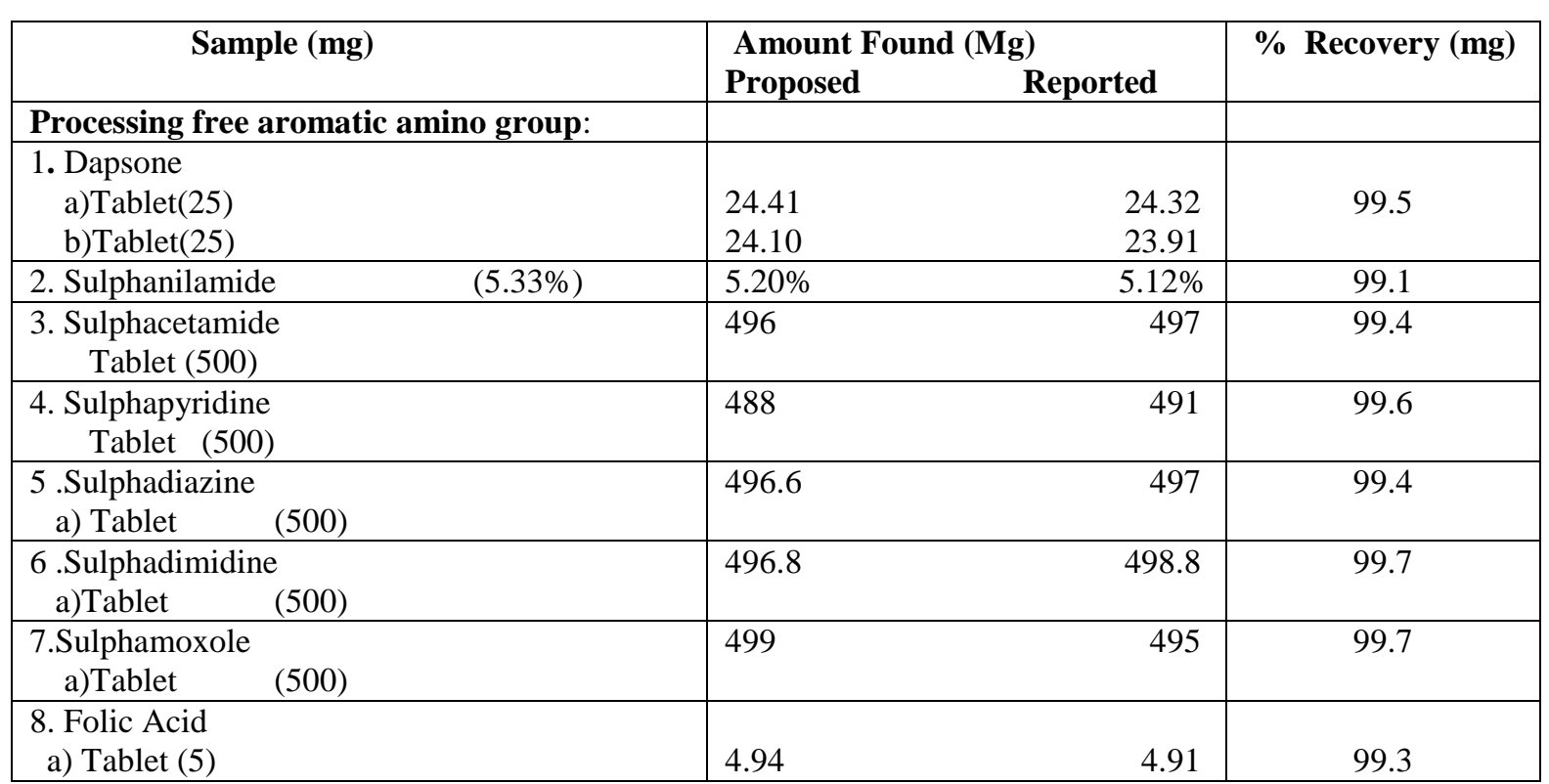


Visible Spectrophotometric Method for the Determination of Pharmaceutically Important Aromatic Primary Amines by using P-N, N-Dimethylphenylenediamine and Iodine

\begin{tabular}{|c|c|c|c|}
\hline $\begin{array}{l}\text { b) Folic acid } \\
\text { Vit. }_{12}(0.20)\end{array}$ & 1.91 & 1.93 & \\
\hline \multicolumn{4}{|l|}{$\begin{array}{l}\text { producing primary aryl emino group after } \\
\text { hydrolysis: }\end{array}$} \\
\hline 9. Phthalyloulpha-thiazole- $\quad$ Sole (500) & 493.5 & 494.3 & 98.8 \\
\hline \multicolumn{4}{|l|}{$\begin{array}{l}\text { Producing primary aromatic group after } \\
\text { reduction }\end{array}$} \\
\hline $\begin{array}{l}\text { 10. chloramphenicol } \\
(\text { succinate }(1 \mathrm{~kg}))\end{array}$ & $0.971 \mathrm{~g}$ & $0.964 \mathrm{~g}$ & 98.6 \\
\hline
\end{tabular}

Figure1.
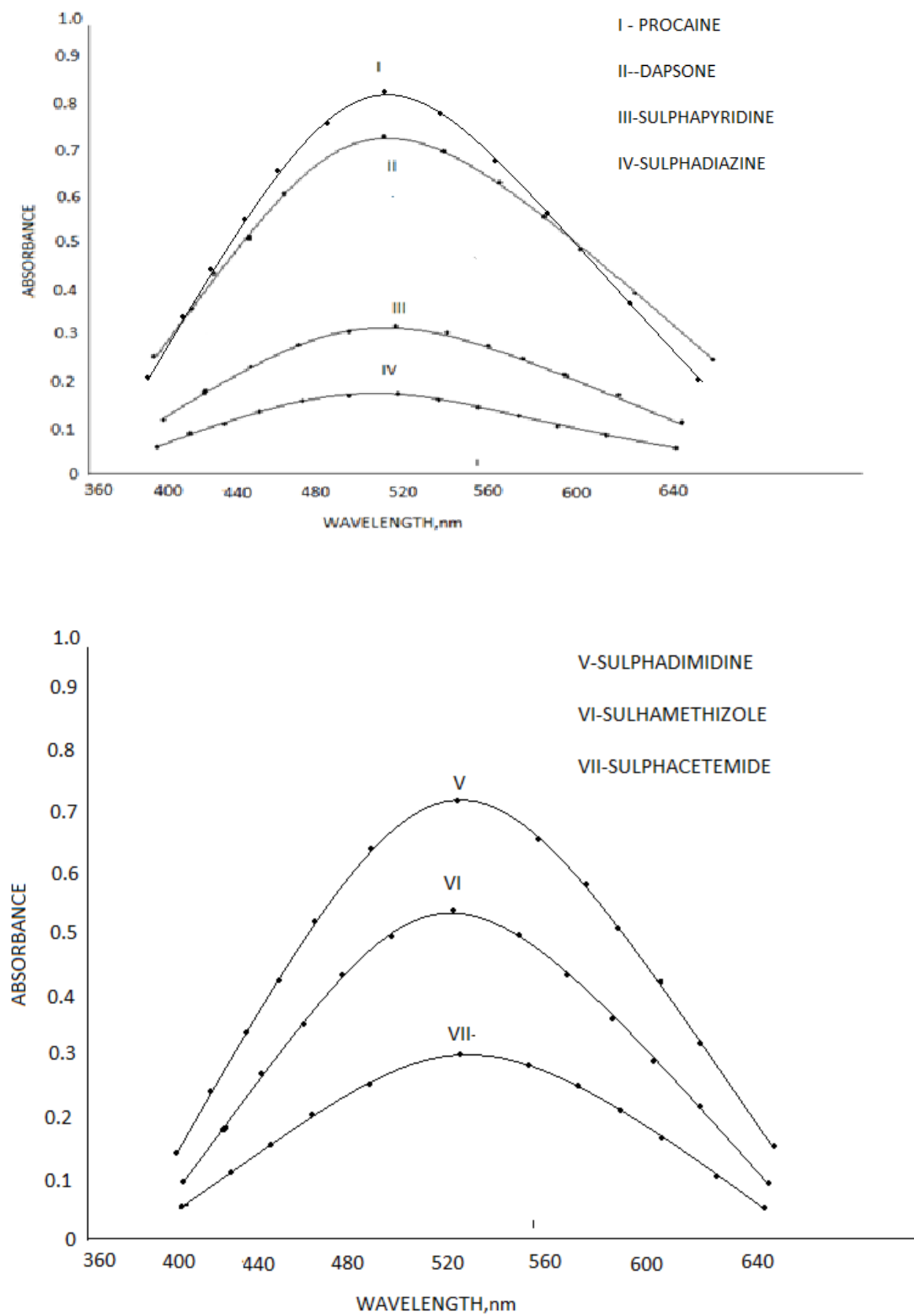


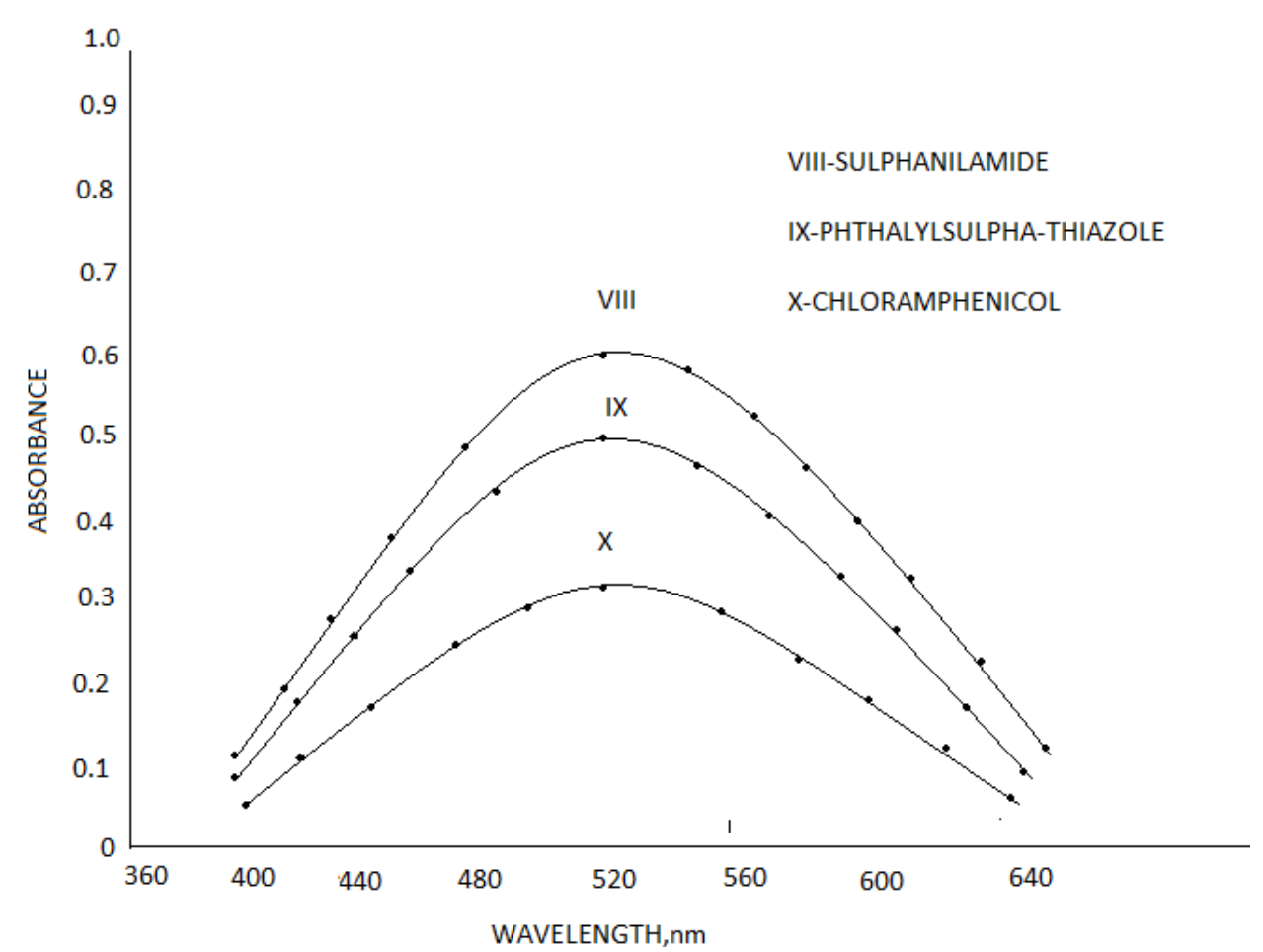

Figure2.

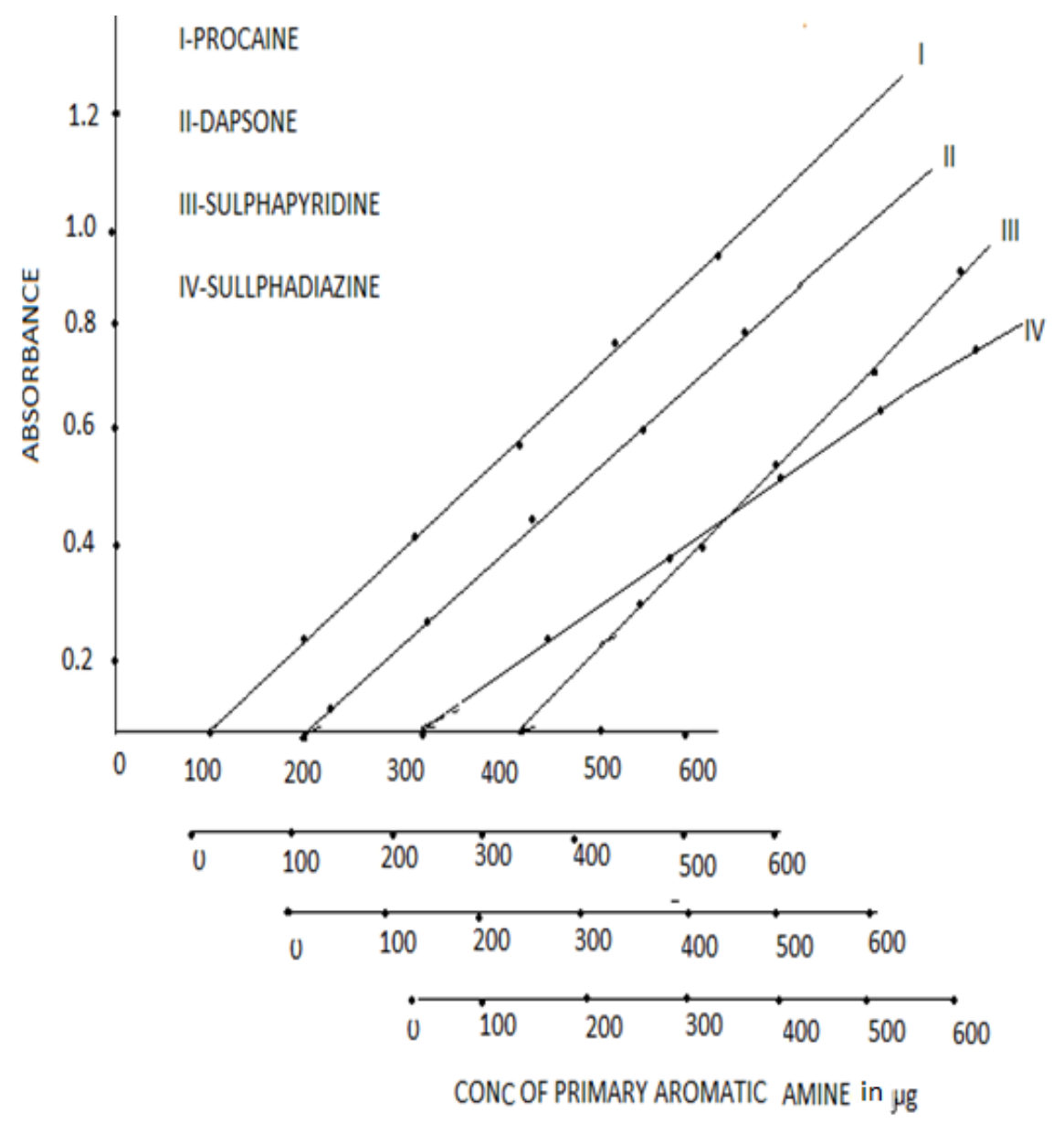


Visible Spectrophotometric Method for the Determination of Pharmaceutically Important Aromatic Primary Amines by using P-N, N-Dimethylphenylenediamine and Iodine
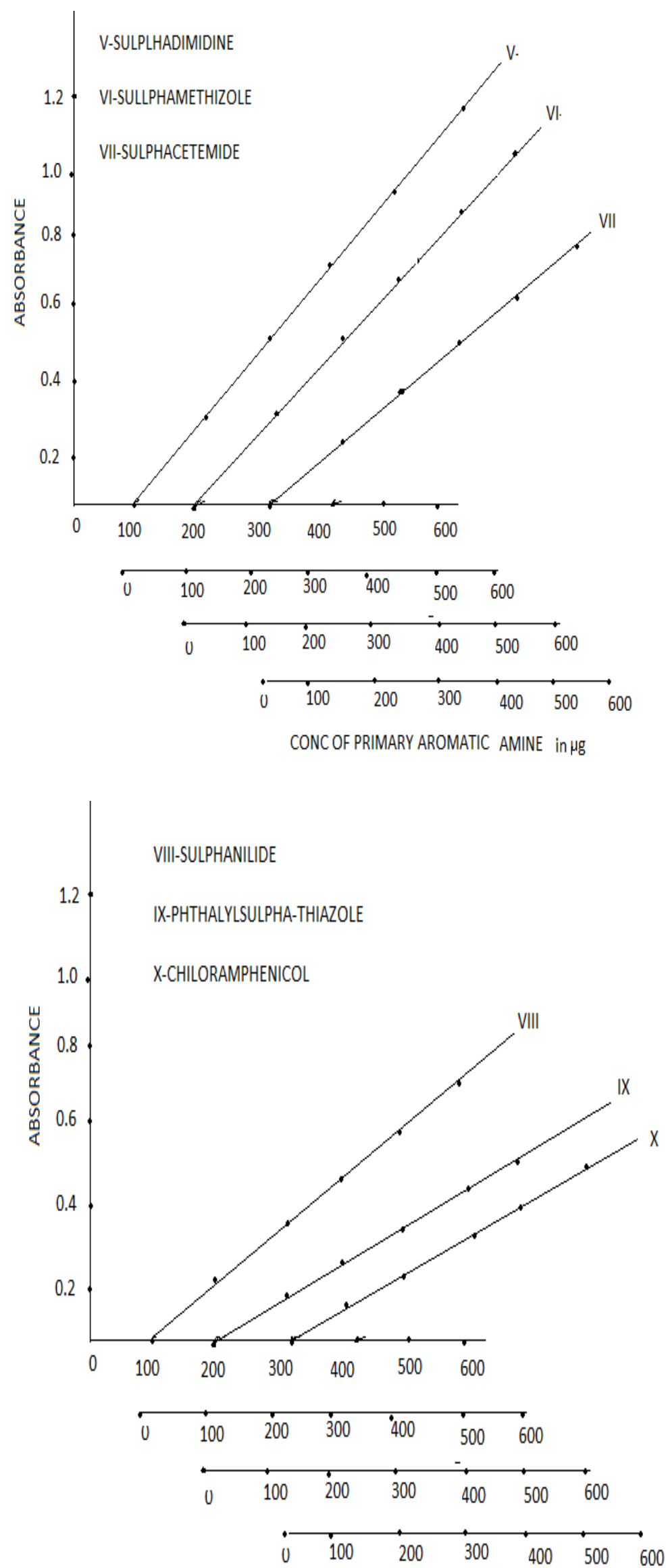

CONC OF PRIMARY AROMATIC AMINE in $\mu \mathrm{g}$ 


\section{REFERENCES}

[1] N.D.Oheronis and T.S.Ma., 'Organic Functional Group Analysis', Inter Science., new York, 229 (1964).

[2] F.D. snell and C.T. Snell 'Colorimetric methods of Analysis '., Robert E. Krieger publishers, New York, 4, 197(1964).

[3] Idem.,ibid.D.VanNostrand company, Princeton New Jersey.,4A, 369 (1967).

[4] S. Patal, 'The chemistry of the Amino Group' Inter-science, New York., 81, 160, 323 (1968).

[5] (a) J.T. Woods and G.H. Schneller 'pharmaceutical analysis', Editors T. Higuchi and E. Brochmenn-Hansien., Interscience, London, 137 (1961).

(b) S. Siggia and H.J. Gordan., 'Quantitative organic Analysis Via Functional Groups ', John Wiley and Sons, Interscience, New York, 4, 83 (1979).

[6] R.K. Gilpin,L.A.Pachla and J.S. Renweller, Anal. Chem., 53,14R (1981). W.T.Smith Jr.and J.M. Patterson, Anal Chem., 54, 58R (1982).

[7] I.T. Miller and H.D. Springall, 'Shorter Sidgwick's Organic Chemistry of Nitrogen', Clarendon press, Oxford, 76 (1969).

[8] E.H. Rodd 'chemistry of Carbon Componds' A modern Comprehensive treatise, Elsevier publishing company, New York, IIIA, 158 (1954).

[9] V.I. Korotkova and V.V Noskov.,Zh Analit. Khin 27. 580 (1972), A.A. 25, 941 (1973).

[10] V.I. Korotkova, V.V.Nosov and V.D. chistota 2av lab., 41, 287 (1975), A.A.29, 5049(1975).

(a) L.Vignoli ,B. Cristau and J.P. Defretin, Annais pharm. Fr. 23,715 (1965).

(b) C.T.H Ellcock and A.C. Fogg, lab. Pract., 23, 555 (1974).

[11] (a) H.Schiff, Ann.Chem., 131, 118 (1864).

(b) R.W. Layer, Chem.Rev.,63, 489 (1963).

[12] (a) C. Menzie, Anal. Chem. 28, 1321 (1956).

(b) S.Patal,'The Chemistry of Double Bond ', Interscience, London (1970).

(c) K. Dey, J .Sci. Ind Res., 33, 76 (1974). 